\title{
The Influence of Age on Central Effects of Methylnaltrexone in Patients with Opioid-Induced Constipation
}

\author{
Solomon S. Liao ${ }^{1}$ (1) $\cdot$ Neal E. Slatkin ${ }^{2,3} \cdot$ Nancy Stambler $^{4}$
}

Accepted: 28 February 2021 / Published online: 31 March 2021

(c) The Author(s) 2021, corrected publication 2021

\begin{abstract}
Background Methylnaltrexone, a peripherally acting $\mu$-opioid receptor antagonist approved for the treatment of opioidinduced constipation (OIC), has restricted diffusion across the blood-brain barrier (BBB) and has not been demonstrated to impact opioid-induced central analgesia. Age-related changes in BBB permeability may compromise methylnaltrexone's restricted diffusion and alter opioid-induced central analgesic effects.

Objective This analysis evaluated whether opioid analgesia is compromised in older adults receiving methylnaltrexone for OIC.

Methods The analysis included adults diagnosed with OIC who received opioids for pain management and who had a terminal illness or chronic nonmalignant pain. Data were pooled from four randomized, double-blind trials and stratified by age ( $<65$ years and $\geq 65$ years). Endpoints included pain intensity scores, symptoms of opioid withdrawal, treatment-related adverse events (TRAEs), and rescue-free laxation (RFL) within $4 \mathrm{~h}$ of treatment.

Results Overall, 1323 patients were $<65$ years of age ( $n=908$, methylnaltrexone; $n=415$, placebo) and 304 patients were $\geq 65$ years of age ( $n=171$, methylnaltrexone; $n=133$, placebo). Nonsignificant pain intensity score reductions were observed in all groups. In the older cohort, measures of opioid withdrawal did not show statistical differences from baseline in either the methylnaltrexone or placebo groups. The most frequently reported TRAEs were abdominal pain, flatulence, and nausea. Relative to the first dose, gastrointestinal TRAEs potentially related to opioid withdrawal declined with the second dose and were comparable with placebo, regardless of age. RFL response within $4 \mathrm{~h}$ of methylnaltrexone treatment increased significantly in both age cohorts relative to placebo.

Conclusions Methylnaltrexone use did not adversely affect pain control, opioid withdrawal effects, or AEs while providing effective RFL, regardless of age. These results suggest that age does not appear to influence the safety and efficacy of methylnaltrexone for OIC. Further research is needed to assess the impact of other factors that alter BBB permeability, such as dementia, stroke, or drug interactions, on the safety and efficacy of methylnaltrexone.

Clinical Trial Registration Numbers Study 302, NCT00402038; study 3200K1-4000, NCT00672477; study 3200K1-3356, NCT00529087; study 3201, NCT01186770.
\end{abstract}

Solomon S. Liao

ssliao@hs.uci.edu

1 Palliative Care Service Hospitalist Program, University of California Irvine Medical Center, 101 South City Drive, Bldg 26, ZC4076H, Orange, CA 92868, USA

2 University of California Riverside, School of Medicine, Riverside, CA, USA

3 Medical Affairs, Salix Pharmaceuticals, Bridgewater, NJ, USA

4 Clinical Research, Progenics Pharmaceuticals, Inc., a subsidiary of Lantheus Holdings Inc., New York, NY, USA

\section{Key Points}

Use of methylnaltrexone for opioid-induced constipation (OIC) does not adversely affect opioid central analgesia, adverse effects or opioid withdrawal effects, but does provide effective rescue-free laxation, regardless of age.

Despite a cohort of increased age, methylnaltrexone did not impede opioid pain relief and was effective in treating OIC. 


\section{Introduction}

For patients receiving opioid therapy for pain, constipation is the most bothersome gastrointestinal-related adverse effect $[1,2]$. Opioids inhibit gastric emptying and delay gastrointestinal transit time by binding to gastrointestinal $\mu$-opioid receptors. This hinders normal visceral nerve activity, gut motility, and ion and fluid secretion, leading to constipation [3]. Opioid-induced constipation (OIC) affects up to $86 \%$ of older patients receiving short- or long-term opioid therapy $[4,5]$. However, overall constipation prevalence increases with age [6] for many reasons in addition to opioid therapy. Factors including electrolyte abnormalities and comorbidities (e.g. diabetes and chronic renal disease) increase the risk for developing constipation unrelated to opioids and also increase the risk of developing OIC [5].

Opioid and opioid antagonist effects on the central nervous system (CNS) may be dependent on blood-brain barrier (BBB) integrity. The BBB is a web of microvessels lined with specialized endothelial cells that segregate CNS compounds and export toxic chemicals out of the CNS [7]. With aging, physiologic changes to BBB endothelial cells occur that may increase $\mathrm{BBB}$ penetrance, potentially impairing the brain's normal influx and clearance of molecules [8]. For example, the aging process can loosen the tight junctions that connect the BBB endothelial cells [8], leading to increased BBB permeability, neuroinflammation, and neurodegeneration [8-11]. In addition, age-related decreases in transporter numbers on BBB neurovascular endothelial cells may reduce proper amino acid and toxic compound elimination [9].

Nonspecific opioid receptor antagonists with central and peripheral effects, such as naloxone and naltrexone, can effectively treat OIC, but typically impact central opioid analgesia by crossing the BBB [12]. Methylnaltrexone is a selective, peripherally acting $\mu$-opioid receptor antagonist that inhibits opioid-induced increases in oral-cecal transit time and time to gastric emptying [13-15]. Because of its low lipid solubility and strong polarity, methylnaltrexone has restricted diffusion across the intact BBB [16]. Consequently, methylnaltrexone blocks the gastrointestinal opioid receptors that induce OIC, but does not reduce opioid CNS analgesic efficacy [3]. However, it is unknown if age-related increases in BBB penetrance could potentially allow methylnaltrexone, despite its high polarity and low lipid solubility, to leach into the CNS across the leaky barrier and compromise opioid analgesic efficacy. This post hoc analysis pooled patients from four methylnaltrexone studies, stratified them by age ( $<65$ years or $\geq 65$ years), and assessed if opioid analgesia, withdrawal effects, safety, and laxation response are affected by age.

\section{Methods}

\subsection{Study Design}

Data were pooled from four randomized, double-blind, placebo-controlled trials (study 302, NCT00402038; study 3200K1-4000, NCT00672477; study 3200K1-3356, NCT00529087; study 3201, NCT01186770) that included adults diagnosed with OIC who received opioids for pain management. Each study had been previously reported [12, 17-19], received local or central Institutional Review Board approval, followed good clinical practice and Declaration of Helsinki principles, and obtained pre-enrollment patient written informed consent.

\subsection{Participants}

Eligibility criteria for each primary study have been previously reported [12, 17-19]. Briefly, studies 302 and 4000 enrolled adult patients with OIC and terminal illnesses who had life expectancies of $\geq 1$ month and who received stable opioid regimens for 2 weeks before the first treatment dose. In those studies, OIC was defined as (1) fewer than three laxations during the previous week and no clinically significant laxation in the $24 \mathrm{~h}$ before the first treatment dose, or (2) no clinically significant laxation within $48 \mathrm{~h}$ before the first treatment dose. Studies 3201 and 3356 enrolled adult patients with OIC and chronic nonmalignant pain for $\geq 2$ months who received $\geq 50 \mathrm{mg} /$ day of oral morphine equivalent doses for $\geq 14$ days before the first treatment dose. For these studies, OIC was defined as fewer than three rescuefree bowel movements (RFBMs) per week associated with one or more of the following signs and symptoms.

- Study 3356: hard or lumpy stools, straining during bowel movements, a sensation of incomplete evacuation after bowel movements.

- Study 3201: $\geq 25 \%$ of RFBMs categorized as type 1 or 2 on the Bristol Stool Form Scale, straining during 25\% of RFBMs, $\geq 25 \%$ of RFBMs with a sensation of incomplete evacuation.

Key exclusion criteria for all studies included individuals with a history of methylnaltrexone treatment, those who were pregnant or breastfeeding, and those with bowel obstruction or impaction (which in the investigator's opinion might have been primarily responsible for constipation). Full eligibility criteria were previously reported [12, 17-19]. 


\subsection{Study Designs/Interventions}

Each study had a double-blind treatment period; studies 302, 4000, and 3356 also had open-label treatment periods. In study 302 , patients received subcutaneous methylnaltrexone $0.15 \mathrm{mg} / \mathrm{kg}$ or placebo every other day for 2 weeks. Dose escalation to $0.30 \mathrm{mg} / \mathrm{kg}$ or equivalent placebo volume was allowed during the second week. In study 4000, patients were stratified based on body weight, and were then randomized to receive subcutaneous methylnaltrexone $8 \mathrm{mg}$ or placebo (weight $38-<62 \mathrm{~kg}$ ) or subcutaneous methylnaltrexone $12 \mathrm{mg}$ or placebo (weight $\geq 62-114 \mathrm{~kg}$ ) every other day for 2 weeks. Patients who were outside of these body weight ranges (i.e. $<38 \mathrm{~kg}$ or $>114 \mathrm{~kg}$ ) were administered a dose of $0.15 \mathrm{mg} / \mathrm{kg}$. For study 3356 , subcutaneous methylnaltrexone $12 \mathrm{mg}$ once daily, $12 \mathrm{mg}$ once every other day, or placebo was administered for 4 weeks. In study 3201, oral methylnaltrexone 150,300 , or $450 \mathrm{mg}$ or placebo was administered daily for 4 weeks.

In studies 302 and 4000, patients could continue receiving laxatives if their regimen at baseline had been stable for $>3$ days before the first dose; patients could take other laxatives as needed but not within $4 \mathrm{~h}$ before or after receiving the study drug. In studies 3356 and 3201, patients who did not have a bowel movement for 3 days were permitted to take bisacodyl tablets for rescue.

\subsection{Assessments}

Endpoints in this post hoc analysis were analyzed in the pooled populations from the primary methylnaltrexone trials stratified by age ( $<65$ and $\geq 65$ years) and included changes in pain scores, symptoms of opioid withdrawal, treatmentrelated adverse events (TRAEs), and rescue-free laxation (RFL) response within $4 \mathrm{~h}$ of treatment. Pain scores were evaluated based on a pain intensity scale, with 0 indicating no pain and 10 indicating worst possible pain. Mean current and worst pain scores were reported at baseline and $4 \mathrm{~h}$ postdose for studies 302 and 4000, while mean pain intensity scores were reported at baseline and at weeks 2 and 4 for studies 3356 and 3201.

Symptoms of opioid withdrawal were evaluated using the Objective and Subjective Opiate Withdrawal Scales (OOWS and SOWS) in studies 3356 and 3201. For the OOWS, clinicians assigned a score of 0 (absence) or 1 (presence) for 13 symptoms indicating opioid withdrawal, with a total possible score of 13 [20]. For the SOWS, patients rated their perceived severity of 19 opioid withdrawal symptoms on a scale from 0 (not at all) to 4 (extremely), with a total possible score of 76. This version of the SOWS included three additional symptoms (trouble sleeping, poor appetite, and diarrhea) to be reflective of the OIC population. Each scale was also evaluated excluding cramping, a common symptom associated with constipation and methylnaltrexone treatment. Symptoms of opioid withdrawal were evaluated in study 302 using a modified Himmelsbach Opioid Withdrawal Scale (mHOWS), in which patients rated opioid withdrawal symptoms (rhinorrhea, tremor, piloerection, yawning, perspiration, restlessness, and lacrimation) on a 4-point scale (1 none; 2 mild; 3 moderate; 4 severe). The total possible score ranged from 7 to 28 . Data were collected for each assessment at baseline and the day after receiving each dose.

Safety was evaluated based on the incidence of AEs and their relationship to treatment as assessed by the investigators during the double-blind phases of each study among their respective safety populations. Gastrointestinal TRAEs potentially related to opioid withdrawal on treatment days 1 and 2 were collected by matching Medical Dictionary for Regulatory Activities (MedDRA)-defined TRAEs to the SOWS. Efficacy was assessed by the proportion of patients demonstrating a treatment response, defined as those achieving RFL within $4 \mathrm{~h}$ after the first study drug dose.

\subsection{Statistical Analysis}

Demographics, baseline characteristics, and safety were summarized using descriptive statistics. Efficacy, pain intensity, opioid withdrawal symptoms, and TRAEs were assessed in all randomized patients in the pooled population who received at least one dose of study treatment. Least squares mean changes from baseline in symptoms of opioid withdrawal and pain scores were calculated based on analysis of covariance models with treatment as the main effect and baseline value as a covariate for comparing the treatment groups. Differences in the percentages of patients with RFL within $4 \mathrm{~h}$ after treatment were analyzed using Chi-square tests. Statistical significance was set at 0.05 , with no adjustments for multiplicity. All analyses were conducted using $\mathrm{SAS}^{\circledR}$ version 9.4 (SAS Institute Inc., Cary, NC, USA).

\section{Results}

\subsection{Participants}

Among the 1627 pooled patients, 1323 were $<65$ years of age (subcutaneous methylnaltrexone, $n=359$; oral methylnaltrexone, $n=549$; placebo, $n=415)$ and 304 were $\geq$ 65 years of age (subcutaneous methylnaltrexone, $n=118$; oral methylnaltrexone, $n=53$; placebo, $n=133$ ) (Table 1). The mean age was 49.5 years in the younger cohort and 74.2 years in the older cohort. The majority of patients were women in the younger cohort and men in the older cohort. Most participants were White (> 85\%) and there were no meaningful differences between treatment groups with regard to race or ethnicity. A higher proportion of patients 
Table 1 Baseline demographics and disease characteristics

\begin{tabular}{|c|c|c|c|c|}
\hline & \multicolumn{2}{|c|}{ Patients aged $<65$ years } & \multicolumn{2}{|c|}{ Patients aged $\geq 65$ years } \\
\hline & Placebo $[n=415]$ & All MNTX [ $n=908]$ & Placebo $[n=133]$ & All MNTX $[n=171]$ \\
\hline Age, years [mean $(95 \% \mathrm{CI})]$ & $50.2(49.3-51.0)$ & $49.1(48.5-49.8)$ & $75.2(73.9-76.6)$ & $73.4(72.3-74.6)$ \\
\hline Women $[n(\%)]$ & $283(68.2)$ & $631(69.5)$ & $49(36.8)$ & $78(45.6)$ \\
\hline \multicolumn{5}{|l|}{ Race $[n(\%)]$} \\
\hline White & $355(85.5)$ & $775(85.4)$ & $125(94.0)$ & $160(93.6)$ \\
\hline Black or African American & $45(10.8)$ & $106(11.7)$ & $5(3.8)$ & $10(5.8)$ \\
\hline American Indian or Alaskan Native & $3(0.7)$ & $4(0.4)$ & $1(0.8)$ & $1(0.6)$ \\
\hline Other & $12(2.9)$ & $23(2.5)$ & $2(1.5)$ & 0 \\
\hline \multicolumn{5}{|l|}{ Ethnicity $[n(\%)]$} \\
\hline Hispanic or Latino & $21(5.1)$ & $62(6.8)$ & $7(5.3)$ & $11(6.4)$ \\
\hline Non-Hispanic or non-Latino & $394(94.9)$ & $845(93.1)$ & $126(94.7)$ & $160(93.6)$ \\
\hline Missing & 0 & $1(0.1)$ & 0 & 0 \\
\hline Weight, kg [mean (95\% CI)] & $86.4(83.8-88.9)$ & $87.4(85.8-89.0)$ & $73.5(70.0-77.1)$ & $76.3(73.2-79.5)$ \\
\hline Creatine clearance, $\mathrm{mL} / \mathrm{min} / 1.73 \mathrm{~m}^{2}$ [mean $\left.(95 \% \mathrm{CI})\right]$ & $99.8(97.2-102.3)$ & $99.6(97.9-101.3)$ & $64.4(60.2-68.6)$ & $69.0(65.1-72.9)$ \\
\hline AST, U/L [mean (95\% CI)] & $28.5(26.6-30.3)$ & $26.3(25.3-27.4)$ & $26.7(22.0-31.4)$ & $24.7(22.2-27.1)$ \\
\hline ALT, U/L [mean $(95 \%$ CI $)]$ & $29.0(26.8-31.2)$ & $27.1(25.6-28.5)$ & $22.8(18.1-27.5)$ & $19.4(17.7-21.1)$ \\
\hline Total bilirubin, $\mu \mathrm{mol} / \mathrm{L}$ [mean $(95 \% \mathrm{CI})]$ & $6.5(6.0-7.1)$ & $6.2(5.9-6.6)$ & $6.8(6.0-7.6)$ & $6.1(5.6-6.7)$ \\
\hline Patients with cancer at baseline $[n(\%)]$ & $59(14.2)$ & $65(7.2)$ & $55(41.4)$ & $51(29.8)$ \\
\hline Baseline MED, mg/day [mean (95\% CI)] & $301.6(234.2-368.9)$ & $251.9(229.5-274.3)$ & $168.5(135.0-202.1)$ & $226.2(166.8-285.6)$ \\
\hline Mean number of baseline laxatives ${ }^{\mathrm{a}}(95 \% \mathrm{CI})$ & $0.8(0.7-0.9)$ & $0.5(0.5-0.6)$ & $1.8(1.6-2.1)$ & $1.4(1.2-1.6)$ \\
\hline Baseline mean current pain score ${ }^{\mathrm{a}, \mathrm{b}}(95 \% \mathrm{CI})$ & $4.1(3.5-4.7)$ & $4.2(3.7-4.8)$ & $3.4(2.9-4.0)$ & $3.5(3.0-4.1)$ \\
\hline Baseline mean worst pain score ${ }^{a, b}(95 \%$ CI) & $5.7(5.1-6.3)$ & $5.7(5.1-6.3)$ & $4.9(4.3-5.6)$ & $4.9(4.3-5.4)$ \\
\hline Baseline mean pain intensity score $(95 \% \mathrm{CI})$ & $6.4(6.2-6.6)$ & $6.4(6.3-6.5)$ & $5.0(4.1-5.9)$ & $5.8(5.3-6.3)$ \\
\hline Baseline mean OOWS total score ${ }^{\mathrm{d}}(95 \% \mathrm{CI})$ & $0.4(0.2-0.5)$ & $0.3(0.3-0.4)$ & $0.3(0.0-0.6)$ & $0.3(0.0-0.6)$ \\
\hline Baseline mean SOWS total score ${ }^{\mathrm{e}}(95 \% \mathrm{CI})$ & $13.7(12.5-14.9)$ & $12.0(11.3-12.8)$ & $10.3(7.3-13.3)$ & $11.6(9.4-13.7)$ \\
\hline $\begin{array}{l}\text { Baseline mean modified Himmelsbach opioid with- } \\
\left.\text { drawal total score } \text { s }^{(95 \%} \mathrm{CI}\right)\end{array}$ & $8.5(7.8-9.2)$ & $8.7(7.9-9.4)$ & $8.0(7.5-8.5)$ & $8.0(7.6-8.4)$ \\
\hline
\end{tabular}

$A L T$ alanine aminotransferase, $A S T$ aspartate aminotransferase, $C I$ confidence interval, $M E D$ morphine equivalent dose, $M N T X$ methylnaltrexone, OOWS Objective Opiate Withdrawal Scale, SOWS Subjective Opiate Withdrawal Scale

${ }^{a}$ In studies 302 and 4000 only

${ }^{\mathrm{b}}$ Age $<65$ years: placebo group, $n=86$, and MNTX group, $n=80$; age $\geq 65$ years: placebo group, $n=92$, and MNTX group, $n=93$

' In studies 3356 and 3201 only; age $<65$ years: placebo group, $n=326$, and MNTX group, $n=817$; age $\geq 65$ years: placebo group, $n=37$, and MNTX group, $n=75$

${ }^{\mathrm{d}}$ In studies 3356 and 3201 only; age $<65$ years: placebo group, $n=326$, and MNTX group, $n=824$; age $\geq 65$ years: placebo group, $n=37$, and MNTX group, $n=74$

${ }^{\mathrm{e}}$ In studies 3356 and 3201 only; age $<65$ years: placebo group, $n=324$, and MNTX group, $n=820$; age $\geq 65$ years: placebo group, $n=37$, and MNTX group, $n=75$

${ }^{\mathrm{f}}$ In study 302 only; age $<65$ years: placebo group, $n=32$, and MNTX group, $n=23$; age $\geq 65$ years: placebo group, $n=39$, and MNTX group, $n=38$

had cancer at baseline in the older cohort and the mean baseline daily morphine equivalent dose was lower in the younger cohort.

\subsection{Pain Intensity}

Similar changes from baseline in current and worst pain scores were observed for both treatment groups in both age cohorts at $4 \mathrm{~h}$ posttreatment in studies 302 and 4000 (Fig. 1a, b). No significant differences in least squares means were noted between treatment groups.

A significant difference in least squares mean changes from baseline to week 2 in pain intensity scores was observed between treatment groups in the older cohorts in studies 3356 and 3201 (Fig. 1c); however, no significant differences were noted between treatment groups in either age group at 4 weeks (Fig. 1d). 

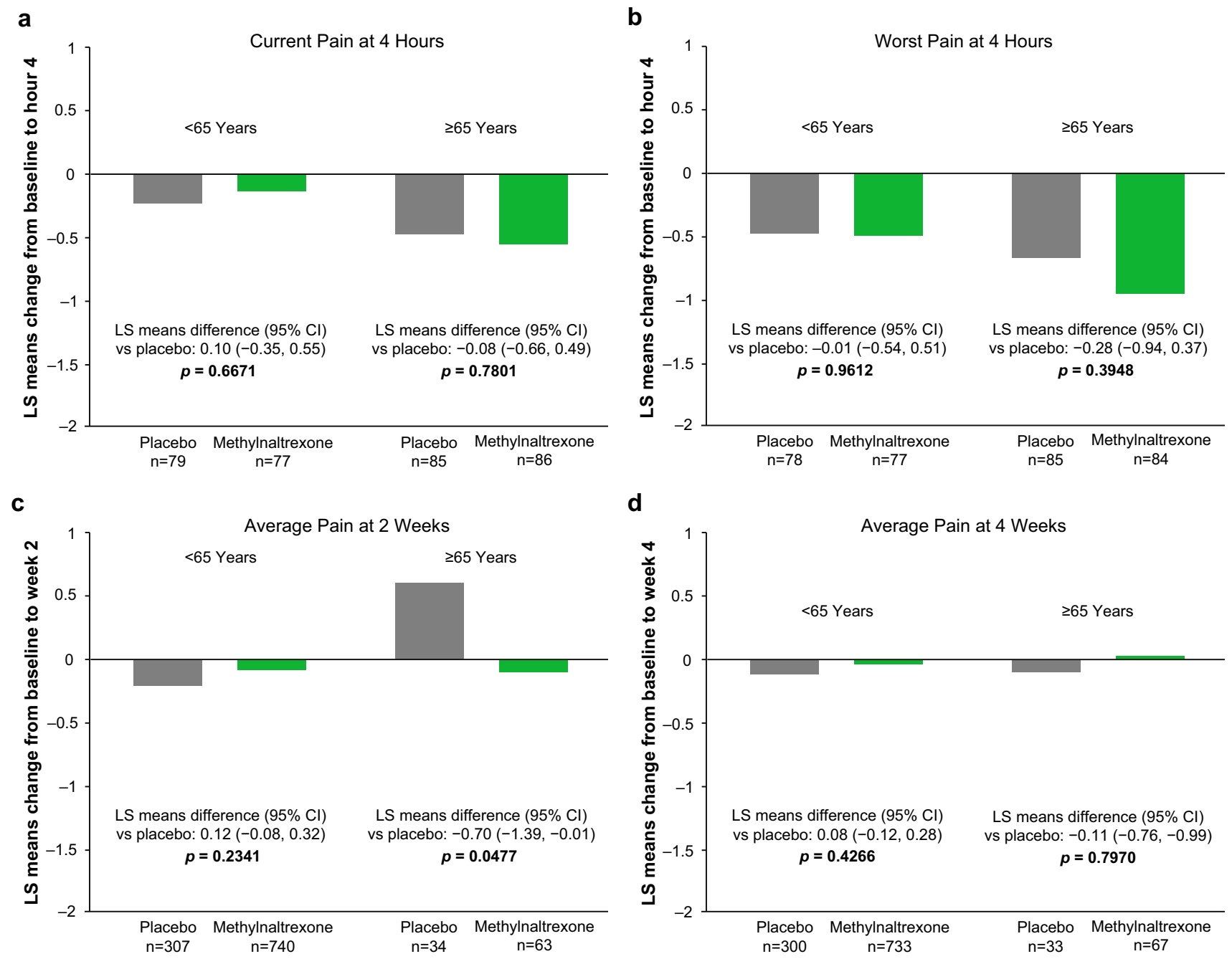

Fig. 1 Changes from baseline in $\mathbf{a}$ current and $\mathbf{b}$ worst pain intensity scores at hour 4 in studies 302 and 4000, and changes from baseline in mean pain intensity scores at $\mathbf{c}$ week 2 and $\mathbf{d}$ week 4 in studies

\subsection{Symptoms of Opioid Withdrawal}

In patients $<65$ years of age, statistically significant differences between treatment groups in least squares mean changes from baseline to day 1 on the OOWS (slight increase) and SOWS (slight decrease) were observed in studies 3356 and 3201 (Fig. 2). Similar findings were observed when the total scores were calculated without cramping included. However, no significant changes from baseline in least squares mean differences in the mHOWS were observed in patients aged $<65$ years in study 302 .

For patients aged $\geq 65$ years, there were no statistical differences between treatment groups in least squares mean changes from baseline to day 1 on the OOWS, SOWS, or

3356 and 3201 among those who were $<65$ years or $\geq 65$ years of age. $C I$ confidence interval, $L S$ least squares

mHOWS (Fig. 2). Similar findings were observed when the total scores excluding cramping were calculated.

\subsection{Adverse Events}

The most frequent TRAEs reported were abdominal pain, flatulence, and nausea (Table 2). The total proportions of patients with one or more TRAEs were similar across treatment and age groups. The overall proportions of patients who experienced gastrointestinal TRAEs potentially related to opioid withdrawal declined from day 1 to day 2 of treatment among those receiving methylnaltrexone, regardless of age (Table 2). The percentages of methylnaltrexone-treated patients reporting gastrointestinal TRAEs potentially related to opioid withdrawal were similar to placebo by day 2 in the 


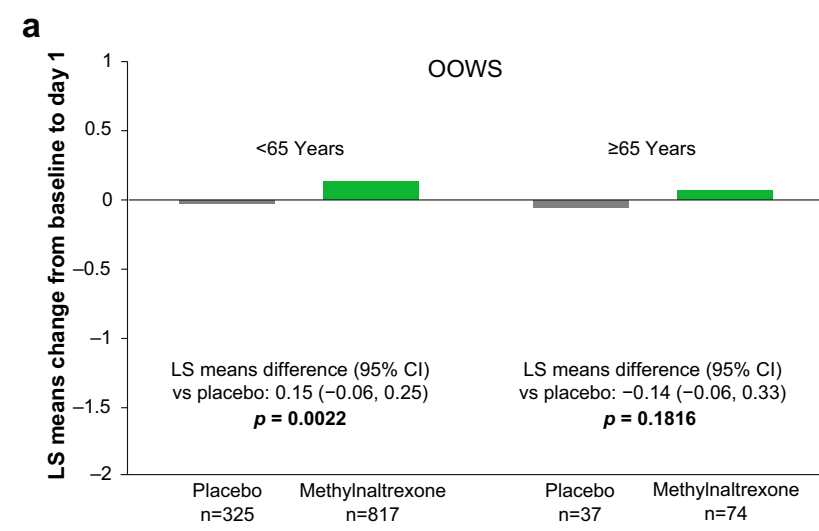

b

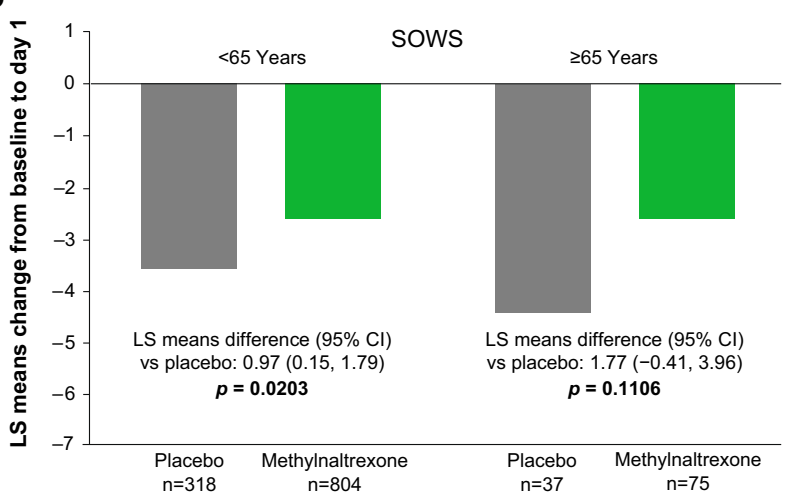

C

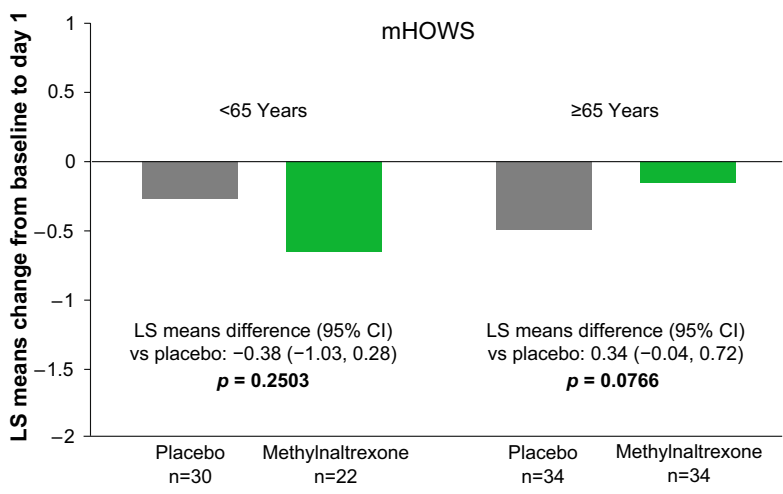

Fig. 2 Changes from baseline in scores among those who were $<65$ years or $\geq 65$ years of age for the a OOWS, $\mathbf{b}$ SOWS, and $\mathbf{c}$ mHOWS at day 1. $m H O W$ modified Himmelsbach Opioid Withdrawal Scale, OOWS Objective Opioid Withdrawal Scale, SOWS Subjective Opioid Withdrawal Scale, $C I$ confidence interval, $L S$ least squares

younger cohort and were less than placebo by day 2 in the older cohort.

\subsection{Efficacy}

Significantly greater percentages of patients achieved RFL within $4 \mathrm{~h}$ after the first dose of methylnaltrexone compared with placebo in both age cohorts (Fig. 3). Patients $\geq 65$ years of age who received methylnaltrexone had a higher response rate than those $<65$ years of age, especially among those receiving subcutaneous methylnaltrexone.

\section{Discussion}

In this post hoc analysis, methylnaltrexone use for the treatment of OIC was evaluated in older patients to discern if the aging brain had an impact on the efficacy and safety of methylnaltrexone, including the effectiveness of opioid treatment. Regardless of age, central opioid analgesic effects were unaffected by methylnaltrexone treatment, as evidenced by the lack of significant changes in pain scores and minor changes in scores measuring symptoms of opioid withdrawal. Increases in pain intensity, an early symptom of opioid withdrawal [21, 22], were not observed in this study, and few patients experienced gastrointestinal TRAEs potentially related to opioid withdrawal. Furthermore, methylnaltrexone treatment significantly increased the percentages of patients who experienced RFLs within $4 \mathrm{~h}$ of treatment. These findings suggest that, despite a cohort of increased age who may have changes in BBB permeability, methylnaltrexone did not impede opioid pain relief and was effective in treating OIC.

As the brain ages, changes to the BBB microvasculature, such as permeability alterations, vessel wall stiffening, neurodegeneration, and tight junction relaxation may contribute to BBB leakiness to certain drugs [9-11]. Consequently, the aging brain may present a challenge to maintaining the safety and efficacy of certain compounds. Methylnaltrexone has limited ability to cross the BBB due to its quaternary structure, which decreases its distribution into the CNS [23]. In this analysis, no significant changes in pain and opioid withdrawal scores were observed in the older cohort, suggesting that methylnaltrexone most likely did not cross the BBB. Surprisingly, significant differences in scores on the OOWS and SOWS were noted between treatment groups in the younger cohort, although for the SOWS, scores decreased for both the placebo and methylnaltrexone groups. As no significant differences were noted in the older cohort (which is more likely to have individuals with compromised BBBs) and no differences in pain were noted between treatment groups, these changes are most likely not clinically significant.

In this pooled analysis, methylnaltrexone use significantly improved RFL within $4 \mathrm{~h}$ of the first dose compared with placebo in both age groups. Interestingly, the RFL response among methylnaltrexone-treated patients was significantly greater in the older cohort than in the younger cohort (44.7\% vs. $28.7 \%, p<0.0001)$. The reasons for this are unknown but may be because the older cohort included more cancer patients and were largely laxative refractory at baseline. Differences in primary study designs or definitions of 


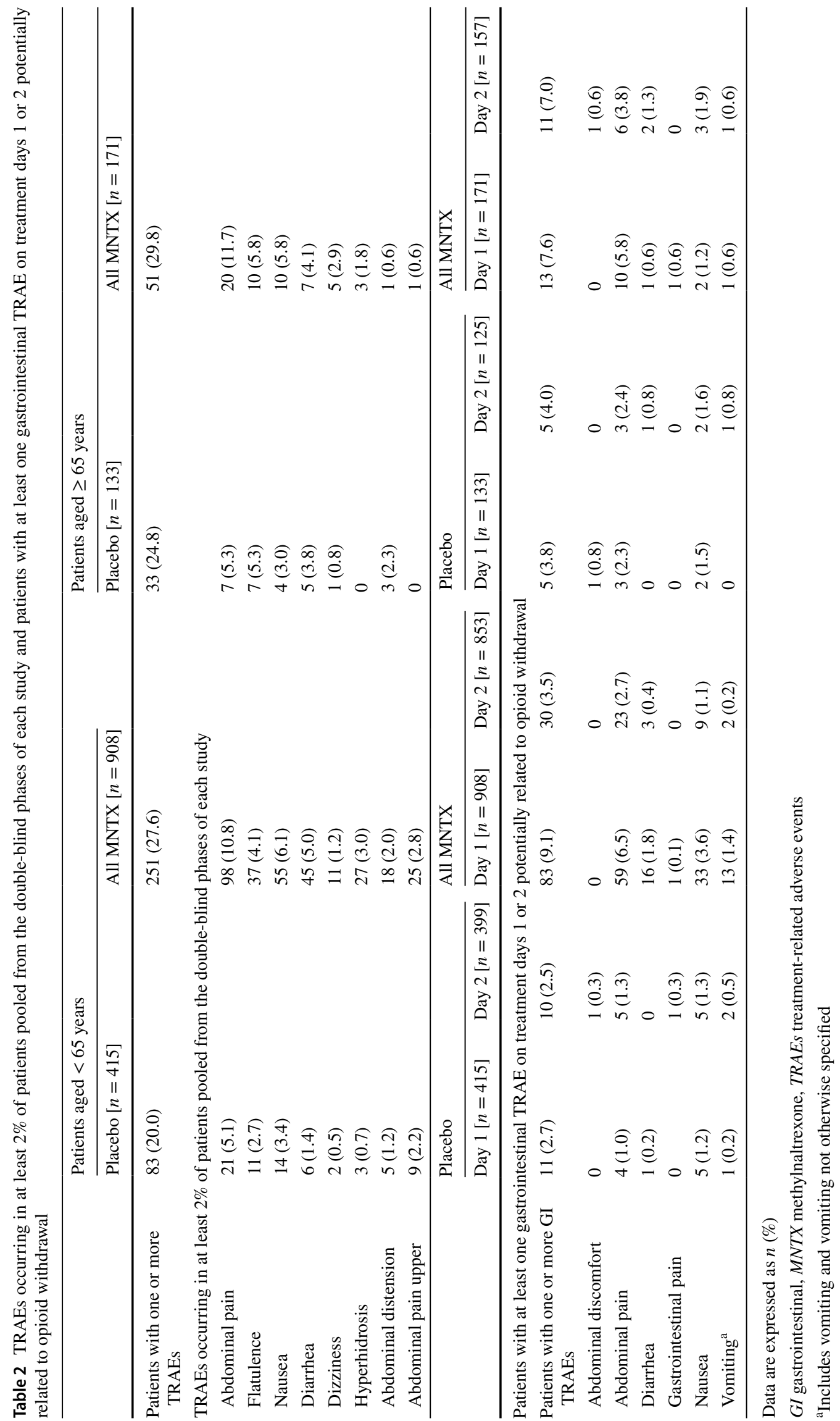




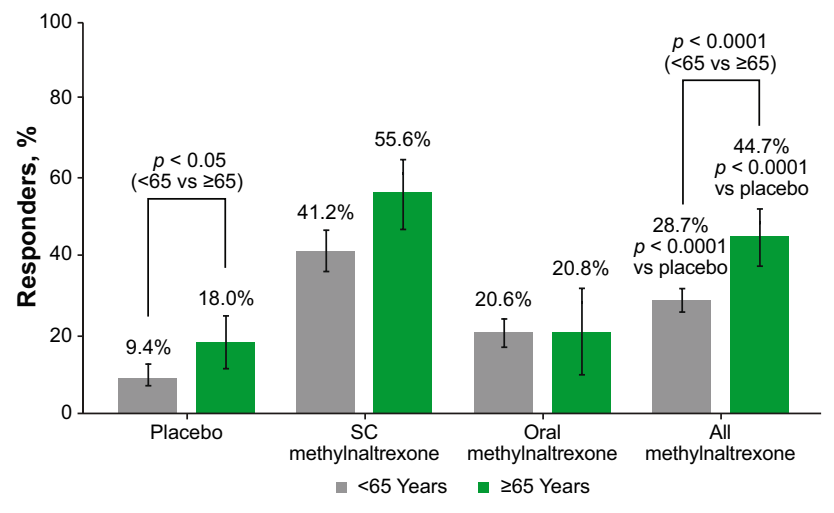

Fig. 3 Percentage of responders with rescue-free laxation within $4 \mathrm{~h}$ after the first dose. $S C$ subcutaneous

RFL response between the advanced illness and the chronic noncancer trials could also be factors that contributed to these differences. Further studies are needed to elucidate the potential implications of this observation.

A special consideration for patients receiving methylnaltrexone is the effect of weight, renal function, and hepatic function on the appropriate dose. Dosing guidelines for patients with advanced illness recommend that subcutaneous methylnaltrexone should be dose-adjusted for body weight $(<38 \mathrm{~kg}=0.15 \mathrm{mg} / \mathrm{kg} ; 38-<62 \mathrm{~kg}=8 \mathrm{mg} ; 62-114$ $\mathrm{kg}=12 \mathrm{mg} ;>114 \mathrm{~kg}=0.15 \mathrm{mg} / \mathrm{kg}$ ) [23]. Body weightbased adjustments are also recommended for patients with advanced illness and moderate to severe renal impairment and in patients with chronic noncancer pain and severe hepatic impairment $(<38 \mathrm{~kg}=0.075 \mathrm{mg} / \mathrm{kg} ; 38-<62 \mathrm{~kg}=$ $4 \mathrm{mg} ; 62-114 \mathrm{~kg}=6 \mathrm{mg} ;>114 \mathrm{~kg}=0.075 \mathrm{mg} / \mathrm{kg}$ ) [23]. In this analysis, differences between age cohorts in baseline liver function tests and creatine clearance were not significant (Table 1). However, the need to correct for renal and hepatic function may be more relevant in the elderly considering the normal decline in renal function and the likelihood of older patients having disease states that may adversely impact renal and hepatic function. A failure to correct for such dysfunctions could lead to higher drug levels that could potentially be associated with a higher incidence of AEs.

AEs are of particular concern among older individuals [24]. This analysis showed little difference between treatment groups with respect to AEs. The only notable exception was abdominal pain, which occurred in a greater percentage of patients receiving methylnaltrexone versus placebo. While abdominal pain could potentially be related to opioid withdrawal, the lack of significant changes in pain scores and minor changes in scores measuring symptoms of opioid withdrawal suggest that this is not the case. Patients may perceive gut peristalsis initiation, which accompanies a normal bowel movement, as pain; therefore, the reported $\mathrm{AE}$ may be a consequence of methylnaltrexone efficacy [12].
In contrast, abdominal distension, a common consequence of constipation, was reported in $2.3 \%$ versus $0.6 \%$ of older patients receiving placebo versus methylnaltrexone. Of note, some patients in studies 3201 and 3356 were randomized to receive treatment with methylnaltrexone every other day; in these patients, treatment day 2 was on study day 3. Overall, methylnaltrexone demonstrated a favorable safety and tolerability profile over the doses and schedules examined in the pooled studies.

\subsection{Limitations}

Several limitations are intrinsic to the design of this post hoc analysis. The use of data pooled from four studies with different dosing, inclusion criteria, patient populations (patients with advanced illness or chronic pain), and administration routes (subcutaneous methylnaltrexone [three studies] and oral methylnaltrexone [one study]) may limit the conclusions but allowed for evaluation of the overall effects of methylnaltrexone in the pooled population across studies. Different scales and timing were used to assess opioid withdrawal symptoms and pain, which may limit the comparability of these results. Additionally, the numbers of patients $<65$ years of age greatly exceeded the number of patients $\geq 65$ years of age in these analyses. However, the overall effects were consistent across studies and within the pooled population. Our studies did not test for methylnaltrexone penetration across the BBB (such as by measuring cerebrospinal fluid concentrations, radiolabeled methylnaltrexone), nor did they take into account the numerous other factors that may alter BBB permeability (e.g. systemic inflammation, dementia, stroke, or potential drug interactions involving CNS drug transporters). Furthermore, our pooled studies did not have enough patients with neurologic conditions $(<3 \%)$, nor did we collect data on the cognitive status of patients to fully understand the impact, if any, of BBB permeability changes on the use of methylnaltrexone in these subsets. The effect of methylnaltrexone among older adults with dementia remains unknown. Further research into the impact of these conditions on BBB permeability for patients who receive methylnaltrexone is needed.

\section{Conclusions}

In this post hoc pooled analysis, methylnaltrexone use among those $<65$ years and $\geq 65$ years of age did not adversely affect pain control, opioid withdrawal effects, or AEs, but provided effective RFL. These data suggest that age does not impact the safety and efficacy of methylnaltrexone.

Acknowledgements Technical editorial and medical writing assistance was provided under the direction of the authors by Dana A. 
Franznick, PharmD, of Echelon Brand Communications, LLC, an OPEN Health company. Funding for this assistance was provided by Salix Pharmaceuticals.

\section{Declarations}

Funding This study was funded by Salix Pharmaceuticals, a division of Bausch Health US, LLC, Bridgewater, NJ, USA, which has licensed the rights to develop and commercialize Relistor ${ }^{\circledR}$ from Progenics Pharmaceuticals, Inc., New York, NY, USA, a wholly owned subsidiary of Lantheus Holdings, Inc., North Billerica, MA, USA.

Conflict of interest Solomon S. Liao has no disclosures to report; Neal E. Slatkin is an employee and shareholder of Salix Pharmaceuticals, a division of Bausch Health US, LLC; and Nancy Stambler is a full-time employee of Progenics Pharmaceuticals.

Ethics approval Each study received local or central Institutional Review Board approval and followed good clinical practice and Declaration of Helsinki principles.

Consent Each study obtained pre-enrollment patient written informed consent.

Data sharing statement The datasets generated and/or analyzed during the current study are not publicly available at this time due to the proprietary nature of this information. Requests for additional information should be made to the corresponding author.

Code availability Not applicable.

Author contributions All authors made substantial contributions to conception, design, and interpretation of the analysis; participated in revising the manuscript critically for important intellectual content; and provided final approval of the manuscript.

Open Access This article is licensed under a Creative Commons Attribution-NonCommercial 4.0 International License, which permits any non-commercial use, sharing, adaptation, distribution and reproduction in any medium or format, as long as you give appropriate credit to the original author(s) and the source, provide a link to the Creative Commons licence, and indicate if changes were made. The images or other third party material in this article are included in the article's Creative Commons licence, unless indicated otherwise in a credit line to the material. If material is not included in the article's Creative Commons licence and your intended use is not permitted by statutory regulation or exceeds the permitted use, you will need to obtain permission directly from the copyright holder. To view a copy of this licence, visit http://creativecommons.org/licenses/by-nc/4.0/.

\section{References}

1. Bell TJ, Panchal SJ, Miaskowski C, Bolge SC, Milanova T, Williamson R. The prevalence, severity, and impact of opioid-induced bowel dysfunction: results of a US and European Patient Survey (PROBE 1). Pain Med. 2009;10(1):35-42.

2. Cook SF, Lanza L, Zhou X, Sweeney CT, Goss D, Hollis K, et al. Gastrointestinal side effects in chronic opioid users: results from a population-based survey. Aliment Pharmacol Ther. 2008;27(12):1224-32.

3. Pergolizzi JV Jr, Raffa RB, Pappagallo M, Fleischer C, Pergolizzi J 3rd, Zampogna G, et al. Peripherally acting mu-opioid receptor antagonists as treatment options for constipation in noncancer pain patients on chronic opioid therapy. Patient Prefer Adherence. 2017;11:107-19.

4. Chey WD, Webster L, Sostek M, Lappalainen J, Barker PN, Tack J. Naloxegol for opioid-induced constipation in patients with noncancer pain. N Engl J Med. 2014;370(25):2387-96.

5. Chokhavatia S, John ES, Bridgeman MB, Dixit D. Constipation in elderly patients with noncancer pain: focus on opioid-induced constipation. Drugs Aging. 2016;33(8):557-74.

6. Gallegos-Orozco JF, Foxx-Orenstein AE, Sterler SM, Stoa JM. Chronic constipation in the elderly. Am J Gastroenterol. 2012;107(1):18-25.

7. Zenaro E, Piacentino G, Constantin G. The blood-brain barrier in Alzheimer's disease. Neurobiol Dis. 2017;107:41-56.

8. Erdo F, Denes L, de Lange E. Age-associated physiological and pathological changes at the blood-brain barrier: a review. J Cereb Blood Flow Metab. 2017;37(1):4-24.

9. Marques F, Sousa JC, Sousa N, Palha JA. Blood-brain-barriers in aging and in Alzheimer's disease. Mol Neurodegener. 2013;8:38.

10. Oakley R, Tharakan B. Vascular hyperpermeability and aging. Aging Dis. 2014;5(2):114-25.

11. Montagne A, Barnes SR, Sweeney MD, Halliday MR, Sagare AP, Zhao Z, et al. Blood-brain barrier breakdown in the aging human hippocampus. Neuron. 2015;85(2):296-302.

12. Bull J, Wellman CV, Israel RJ, Barrett AC, Paterson C, Forbes WP. Fixed-dose subcutaneous methylnaltrexone in patients with advanced illness and opioid-induced constipation: results of a randomized, placebo-controlled study and open-label extension. J Palliat Med. 2015;18(7):593-600.

13. Murphy DB, Sutton JA, Prescott LF, Murphy MB. Opioid-induced delay in gastric emptying: a peripheral mechanism in humans. Anesthesiology. 1997;87(4):765-70.

14. Siemens W, Becker G. Methylnaltrexone for opioid-induced constipation: review and meta-analyses for objective plus subjective efficacy and safety outcomes. Ther Clin Risk Manag. 2016;12:401-12.

15. Slatkin N, Thomas J, Lipman AG, Wilson G, Boatwright ML, Wellman C, et al. Methylnaltrexone for treatment of opioidinduced constipation in advanced illness patients. J Support Oncol. 2009;7(1):39-46.

16. Yuan CS, Foss JF. Methylnaltrexone: investigation of clinical applications. Drug Dev Res. 2000;50(2):133-41.

17. Michna E, Blonsky ER, Schulman S, Tzanis E, Manley A, Zhang $\mathrm{H}$, et al. Subcutaneous methylnaltrexone for treatment of opioidinduced constipation in patients with chronic, nonmalignant pain: a randomized controlled study. J Pain. 2011;12(5):554-62.

18. Rauck R, Slatkin NE, Stambler N, Harper JR, Israel RJ. Randomized, double-blind trial of oral methylnaltrexone for the treatment of opioid-induced constipation in patients with chronic noncancer pain. Pain Pract. 2017;17(6):820-8.

19. Thomas J, Karver S, Cooney GA, Chamberlain BH, Watt CK, Slatkin NE, et al. Methylnaltrexone for opioid-induced constipation in advanced illness. N Engl J Med. 2008;328(22):2332-43.

20. Handelsman L, Cochrane KJ, Aronson MJ, Ness R, Rubinstein KJ, Kanof PD. Two new rating scales for opiate withdrawal. Am J Drug Alcohol Abuse. 1987;13(3):293-308.

21. Cowan DT, Wilson-Barnett J, Griffiths P, Allan LG. A survey of chronic noncancer pain patients prescribed opioid analgesics. Pain Med. 2003;4(4):340-51.

22. Redding SE, Liu S, Hung WW, Boockvar KS. Opioid interruptions, pain, and withdrawal symptoms in nursing home residents. Clin Ther. 2014;36(11):1555-63.

23. Relistor [package insert]. Bridgewater, NJ: Salix Pharmaceuticals; 2018.

24. Lavan AH, Gallagher P. Predicting risk of adverse drug reactions in older adults. Ther Adv Drug Saf. 2016;7(1):11-22. 